\title{
Objective Voice Parameters and Self-Perceived Handicap in Dysphonia
}

\author{
Christina Hummel $^{\mathrm{a}}$ Manuela Scharf $^{\mathrm{a}}$ Anne Schuetzenberger ${ }^{\mathrm{a}}$ Elmar Graessel ${ }^{\mathrm{b}}$ \\ Frank Rosanowski ${ }^{a}$ \\ Departments of a Phoniatrics and Pedaudiology, and ${ }^{\mathrm{b}}$ Psychology and Medical Sociology, \\ Erlangen University Hospital, Erlangen, Germany
}

\section{Key Words}

Objective voice parameters $\cdot$ Handicap, self-perceived ·

Dysphonia

\begin{abstract}
Objective: This study focuses on the relation between objective voice quality and the self-perception of a voice handicap. Patients and Methods: The study group consisted of 86 German-speaking patients (51 women, 35 men) suffering from benign dysphonia. The test persons completed the German version of the Voice-Related Quality of Life (V-RQOL) Questionnaire without prior information about their diagnosis and underwent voice analysis with the Dysphonia Severity Index (DSI) being the parameter of this study. Results: No correlation between $\mathrm{V}-\mathrm{RQOL}$ and DSI could be found ( $p>0.05)$. On the V-RQOL, women scored worse than men, but not at a significant level. Patients with dysphonia of organic origin scored significantly worse than patients with functional dysphonia ( $p=0.026$ ). On the DSI, men's values were significantly lower than women's $(p=0.001)$. Organic dysphonia caused significantly lower DSI values than functional dysphonia $(p=0.011)$. Conclusion: Objective voice quality and the individual perception of voice quality by the patient are independent parameters. Both need to be assessed in clinical practice.

Copyright $\odot 2010$ S. Karger AG, Basel
\end{abstract}

\section{Introduction}

In Western communities, communication disorders have a prevalence of $5-10 \%$ [1], with dysphonia being the focus of this study. One third of all people need their voice occupationally [2], and dysphonia is even more prevalent in these persons than in the general population [1-4]. The costs of voice disorders account for up to $3 \%$ of the US gross national product [1]. Besides the economic aspect, dysphonia may influence quality of life [5] not only in the psychological [6], but also in the physical [7] domain.

Following the former International Classification of Impairments, Disabilities and Handicaps [8] by the WHO, the European Laryngological Society (ELS) offers a recommendation for the structural assessment of pathological voices, including not only organic and functional aspects, but also the individual perception of a disease [9]. Videolaryngostroboscopy is the recommended clinical tool for the examination of the larynx $[9,10]$. As regards functional assessment, perception as well as acoustic analyses by computer systems are methods applied [11-15], and a variety of questionnaires and visual analogue scales exist for the self-evaluation of a handicap $[5-7,12,16,17]$.

This study was conducted to answer the following questions:

\section{KARGER}

Fax +4161306 1234

E-Mail karger@karger.ch

www.karger.com
(C) 2010 S. Karger AG, Basel

$1021-7762 / 10 / 0626-0303 \$ 26.00 / 0$

Accessible online at:

www.karger.com/fpl
Christina Hummel

Department of Phoniatrics and Pedaudiology

Erlangen University Hospital, Bohlenplatz 21

DE-91054 Erlangen (Germany)

Tel.+499131 853 3146, E-Mail christina.hummel@googlemail.com 
Table 1. Mean scores $\pm \mathrm{SD}$ and ranges of V-RQOL and DSI

\begin{tabular}{lcccc}
\hline & Women $(\mathrm{n}=51)$ & Men $(\mathrm{n}=35)$ & Functional $(\mathrm{n}=46)$ & Organic $(\mathrm{n}=40)$ \\
\hline V-RQOL, $\%$ & $62 \pm 25$ & $68 \pm 24$ & $70 \pm 25$ & $58 \pm 23$ \\
Range & $5-100$ & $17-100$ & $5-100$ & $15-100$ \\
\hline DSI & $2.61 \pm 2.19$ & $0.77 \pm 2.69$ & $2.51 \pm 2.26$ & $1.12 \pm 2.7$ \\
Range & -2.77 to 6.96 & -4.44 to 5.69 & -3.69 to 6.18 & -4.44 to 6.96 \\
\hline
\end{tabular}

Table 2. Relationship between DSI and V-RQOL

\begin{tabular}{lll}
\hline All patients & $\mathrm{r}_{\mathrm{P}}$ & 0.159 \\
& $\mathrm{p}$ & 0.130 \\
\hline Women & $\mathrm{r}_{\mathrm{P}}$ & 0.208 \\
& $\mathrm{p}$ & 0.131 \\
\hline Men & $\mathrm{r}_{\mathrm{P}}$ & 0.216 \\
& $\mathrm{p}$ & 0.193 \\
\hline Functional & $\mathrm{r}_{\mathrm{P}}$ & -0.076 \\
& $\mathrm{p}$ & 0.617 \\
\hline Organic & $\mathrm{r}_{\mathrm{P}}$ & 0.153 \\
& $\mathrm{p}$ & 0.345 \\
\hline
\end{tabular}

$\mathrm{r}_{\mathrm{P}}=$ Pearson's correlation coefficient; $\mathrm{p}=$ significance, twotailed.

(1) Is there a correlation between voice quality as depicted by the Dysphonia Severity Index (DSI) and the selfperceived voice handicap measured by the Voice-Related Quality of Life (V-RQOL) Questionnaire?

(2) Is there any influence of gender and aetiology on voice and handicap?

\section{Patients and Methods}

One hundred German-speaking patients consecutively presenting to the reporting department took part in this study after they had given their informed consent. Patients with malign diseases of any kind and localization were excluded from the study. In 14 patients, no pathological finding was obtained. Thus, at last the study group consisted of 86 patients, 51 women and 35 men aged between 16 and 79 years (mean: $47.5 \pm 16.2$ years).

According to the recommendation by the ELS [9], all patients underwent a structural assessment by an experienced phoniatrician. A functional voice disorder was diagnosed in 46 patients (with organic manifestation: $\mathrm{n}=4$; without organic manifestation: $\mathrm{n}=42$ ) and an organic voice disorder in 40 patients (paralysis: $\mathrm{n}=17$; benign neoplasia: $\mathrm{n}=13$; inflammations: $\mathrm{n}=6$; others: $\mathrm{n}=4)$.
Without prior information about their individual diagnosis, all patients were asked to complete the German version of the VRQOL Questionnaire as described by Schwanfelder et al. [6]. The DSI was calculated as described by Wuyts et al. [14]. Complete data sets were obtained from all test persons.

Microsoft Excel ${ }^{\circledR}$ (version of 2003) was used to collect and document data, and SPSS-Software ${ }^{\circledR}$ (version 16) was used for statistical analysis. The normal distribution of the V-RQOL and DSI scores was tested using the Kolmogorov-Smirnov method. The patients were clustered into 5 groups: all patients, men, women, functional and organic. Using the independent two-sample t test, statistical significance of differences in the mean values of the $\mathrm{V}$ RQOL and the DSI was tested. The correlation between DSI and V-RQOL grade was analysed by Pearson's rank coefficient.

\section{Results}

In table 1, the results of the V-RQOL Questionnaire and the DSI are presented.

On the V-RQOL Questionnaire, the women scored worse than the men, but not at a significant level ( $p>$ 0.05). The patients with dysphonia of organic origin scored significantly worse than those with functional dysphonia $(p=0.026)$. On the DSI, the men's values were significantly lower than the women's ( $p=0.001)$. Organic dysphonia caused significantly lower DSI values than functional dysphonia $(\mathrm{p}=0.011)$.

In table 2, the correlations (Pearson's $r$ ) between the V-RQOL and DSI values are presented with no significance found either in the whole group or in the subgroups.

\section{Discussion}

In recent years, subjective quality of life has gained an increasing importance in clinical practice. Following the recommendation by the ELS, it is routinely assessed in dysphonic patients [9]. Psychological consequences need to be evaluated by the patients themselves instead of judgement given by another person [18]. Up to now, there 
has been no internationally accepted 'final consent' on how to measure burden due to dysphonia. However, in most cases it is this burden which causes a patient to seek professional help.

For the measurement of subjective burden due to dysphonia, the Voice Handicap Index (VHI) [19] is regarded as the 'gold standard'. It reflects a patient's judgement about the impact of his voice disorder on daily life and can also be used as a tool for outcome measurement. However, the V-RQOL Questionnaire [15] correlates highly with the VHI both in the English [20] and the German version $[21,22]$. Its major advantage compared to the $\mathrm{VHI}$ is that it consists of fewer questions (10 vs. 30 ). This is more practicable regarding the restricted time in clinical practice. Visual analogue scales have been estimated as being too 'simple' because they cannot reflect the complexity of psychological consequences and therefore impede a more precise judgement of a handicap [17]. Thus, the V-RQOL Questionnaire was chosen for this study.

The DSI is a multiparametric method of acoustical voice assessment derived from a multivariate analysis of 387 subjects to describe perceived voice quality by objective measurements [14]. It is based on the weighted combination of important characterizing voice parameters: maximum phonation time, lowest intensity, highest frequency and jitter. The DSI is a valid instrument for distinguishing between pathological and non-pathological voices $[14,23]$ and proved to be appropriate for clinical purposes [11-13, 16, 17]. It is also more sensitive to minimal changes [14] than perceptual measurements such as the GRBAS (Grade, Roughness, Breathiness, Asthenia, Strain) scale, which was the basis for the DSI construction [14].

As a possible alternative in German-speaking countries, the Göttingen Hoarseness Diagram (GHD) [24] has been widely used. This is a 'phonetogram' based on a computerized voice analysis. By recording the phonation of the vowels $/ \varepsilon /$, /a/, /e/, /i/, /o/ and /u/ at comfortable, low and high pitches as well as $/ \varepsilon /$ while reading a text passage, 2 components are assessed: irregularity and noise. The vibrational irregularity of the voice-generating mechanism is calculated from jitter, shimmer and period correlation, and the degree of closure of the vibrating structures by the glottal-to-noise-excitation ratio. The $\mathrm{x}$ values of the phonetogram reflect the irregularity of voice and the $y$ values the noise component. Ellipses are used for interpretation, with the centre representing mean values. Voice pathologies are mapped in specific regions of the GHD [25]. A review of the literature reveals no studies comparing the GHD and the DSI. However, by experience, the disadvantage of the GHD is its poor practicability as each phonetogram consists of 28 vowels being tested and phonated. Thus, the DSI is more appropriate for daily use and was therefore chosen for this study.

The participants of this survey match the characteristics (diagnosis, age and gender) of the long-term average of patients presenting to the reporting department. They are considered to be representative at least of similar highly specialized institutions.

The first aim of this study was to compare the results of the voice analysis and the patients' self-perception of their burden. No significant correlation between DSI and V-RQOL could be found. In the past, several studies on this topic have shown different results. One criterion for the high validity of the constructed DSI value was its highly significant correlation $(r=-0.79 ; \mathrm{p}<0.001)$ with the score of the VHI [14]. However, in comparable study groups, and using similar measures, only a weak or even no relation was found by Behrmann et al., Hsiung et al., Wheeler et al. and Woisard et al. [26-29]. Although the study designs differ in detail, they reinforce the assumption of this study that voice dysbalance on the one hand and the patients' self-perception of their burden on the other hand are independent parameters with a tendency towards a more serious handicap in severe dysphonia. Thus, it may be concluded that objective voice quality cannot reflect the individual perception of burden due to dysphonia.

The second aim of this study was to examine the influence of gender and aetiology on both the V-RQOL Questionnaire and the DSI. Gender did not have a significant influence on the V-RQOL Questionnaire, which confirms the data in the literature $[5,6,16,30]$. In contrast to other diseases [31,32], the subjective burden elicited by dysphonia is not perceived differently by women and men. This is important with regard to methodological aspects, as the V-RQOL Questionnaire [20-22] does not have to be evaluated in a gender-specific way [33].

Surprisingly, in this study, the difference between the DSI values of women and men is statistically significant. The male patients scored worse than the female patients. In the literature, the DSI is regarded to be unisex because the gender-related parameters of highest frequency (higher in female voices) and maximum phonation time (longer in male voices) of pathological as well as of healthy voices appear to be compensated in the DSI formula [14, 30]. Thus, this former assumption may be wrong. Differences in the genders' objective voice quality cannot be explained. In this study, voices with functional dysphonia gained higher DSI values. However, functional dys- 
phonia is not overrepresented in the women group (women functional: $\mathrm{n}=25$; women organic: $\mathrm{n}=26$; men functional: $\mathrm{n}=21$; men organic: $\mathrm{n}=14$ ). Additional research is necessary.

In this study, the patients with dysphonia of organic origin scored significantly worse on the V-RQOL Questionnaire compared with the patients suffering from functional dysphonia. Glas et al. [34] examined whether or not the subjective burden of dysphonic patients is influenced by the fear of having laryngeal cancer. However, there was no significant difference in the scores of the VHI comparing carcinophobic with non-carcinophobic patients either for smokers and former smokers or for non-smokers. The determining factor of a patient's burden due to dysphonia is not cancerophobia but the handicap concerning the activities of daily life. Yet, in contrast to former studies, there is a difference in the self-perception of patients suffering from different types of voice disorders. Former opinion that functional dysphonia constitutes an overemphasis of psychological burden [35] in questionnaires is obsolete by now $[5,6,16,21,26,36$, 37]. It is not justified to classify functional dysphonia as a somatoform disorder. However, the patients of the study may differ not only in their diagnoses, but also in their sociodemographic backgrounds, which may influence the self-perception of a handicap as well.
In this study, the objective voice quality in functional dysphonia measured by the DSI was significantly better than the quality of organic dysphonic voices. The DSI of patients suffering from functional dysphonia was in the range of normal voices. Similar results were found in the literature [11,23]. In a group of 294 patients [23], the median DSI values were statistically significant comparing voices with non-organic dysphonia (DSI $=2.0$ ), vocal fold mass lesion $(\mathrm{DSI}=1.2)$ and vocal fold paralysis (DSI = -0.7 ) with those of a control group (DSI $=4.2$ ). The DSI value of non-organic dysphonia in the studies by Gonnermann and Nawka [11] and Hakkesteegt et al. [23] was higher than 1.6, which constitutes a normal voice quality [14]. As functional voice disorders may be due to wrong voice usage, problems arise especially after a longer speaking time [23] and, thus, the voice quality degrades after voice loading. Measuring the DSI instead can only reflect the voice quality at one specific moment. It cannot show the full scale of dysphonia if the voice has been properly used before. Additional research by using a voice loading test is necessary to proof if the DSI value of functional dysphonia degrades into a pathological range.

This study allows the following conclusion: voice rating by a phoniatrician and the individual perception of the patient are independent parameters, and both need to be assessed in clinical practice as recommended by the ELS [10].

\section{References}

1 Ruben RJ: Redefining the survival of the fittest: communication disorders in the 21st century. Laryngoscope 2000;110:241-245.

-2 Vilkmann E: Voice problems at work: a challenge for occupational safety and health arrangement. Folia Phoniatr Logop 2005;52: $120-125$.

-3 Rantala L, Vilkmann E: Relationship between subjective voice complaints and acoustic parameters in female teachers' voices. J Voice 1999;13:484-495.

4 Smith E, Lemke J, Taylor M, Kirchner HL, Hoffman H: Frequency of voice problems among teachers and other occupations. J Voice 1998;12:480-488.

5 Krischke S, Weigelt S, Hoppe U, Köllner V, Klotz M, Eysholdt U, Rosanowski F: Quality of life in dysphonic patients. J Voice 2005; 19 : 132-137.

-6 Schwanfelder C, Eysholdt U, Rosanowski F, Grässel E: Voice-related quality of life: structure, validity and factors of the German questionnaire (in German). Folia Phoniatr Logop 2008;60:241-248.
7 Krischke S, Hoppe U, Eysholdt U, Köllner V, Rosanowski F: Physical complaints in dysphonic patients (in German). HNO 2005;53: 78-83.

8 World Health Organization: International Classification of Impairments, Disabilities, Handicaps (ICIDH). Geneva, World Health Organization, 1980.

-9 Dejonckere PH, Bradley P, Clemente P, Cornut G, Crevier-Buchmann L, Friedrich G, van de Heyning P, Remacle M, Woisard V: A basic protocol for functional assessment of voice pathology, especially for investigating the efficacy of (phonosurgical) treatments and evaluating new assessment techniques: guideline elaborated by the Committee on Phoniatrics of the European Laryngological Society (ELS). Eur Arch Otorhinolaryngol 2001;258:77-82.

10 Fleischer S, Hess M: The significance of videostroboscopy in laryngological practice. HNO 2006;54:628-634.
11 Gonnermann U, Nawka T: Ergebnisse der Messungen des Dysphonie-Schweregrad-Index (DSI) und des Heiserkeitsgrades von funktionellen Dysphonien vor und nach Therapie; in Clausnitzer V, Miethe E (eds): Stimme - Sprechen - Sprache, ed 1. Idstein, Schulz-Kirchner, 2004, pp 19-26.

12 Sinkiewicz A, Pruszewicz A, Obrebowski A, Wiskirska-Woźnica B, Wojnowski W: Subjective assessment of voice functions among teachers taking part in the rehabilitation program. Otolaryngol Pol 2006;60:391-395.

13 van Lierde KM, Claeys S, de Bodt M, van Cauwenberge P: Long-term outcome of hyperfunctional voice disorders based on a multiparameter approach. J Voice 2007;21: 179-188.

14 Wuyts FL, de Bodt MS, Molenberghs G, Remacle M, Heylen L, Millet B, van Lierde K, Raes J, van de Heyning PH: The Dysphonia Severity Index: an objective measure of vocal quality based on a multiparameter approach. J Speech Lang Hear Res 2000;43:796-809. 
-15 Hogikyan ND, Sethuraman G: Validation of an instrument to measure voice-related quality of life (V-RQOL). J Voice 1999;13: 557-569.

16 Maertens K, de Jong FI: The voice handicap index as a tool for assessment of the biopsychosocial impact of voice problems. B-ENT 2007;3:61-66.

$\checkmark 17$ Speyer R, Wienecke GH, Dejonckere PH: Self-assessment of voice therapy for chronic dysphonia. Clin Otolaryngol Allied Sci 2004; 29:66-74.

18 Schuster M, Lohscheller J, Kummer P, EysholdtU, RosanowskiF: Selbst-und Fremdbewertung der tracheoösophagealen Ersatzstimme Laryngektomierter. 2003. http:// www.egms.de/en/meetings/dgpp2003/ 03dgpp002.shtml (accessed December 3, 2008).

19 Jacobson BH, Johnson A, Grywalski C, Silbergleit A, Jacobson G, Benninger MS, Newman CW: The Voice Handicap Index (VHI): development and validation. Am J Speech Lang Pathol 1997;6:66-70.

-20 Portone CR, Hapner ER, McGregor L, Otto K, Johns MM: Correlation of the Voice Handicap Index (VHI) and the Voice-Related Quality of Life Measure (V-RQOL). J Voice 2007;21:723-727.

-21 Günther S, Rasch T, Klotz M, Hoppe U, Eysholdt U, Rosanowski F: Bestimmung der subjektiven Beeinträchtigung durch Dysphonien: Ein Methodenvergleich. HNO 2005;10:895-900, 902-904.
22 Nawka T, Wiesmann U, Gonnermann U: Validierung des Voice Handicap Index (VHI) in der deutschen Fassung. HNO 2003;51: 921-929.

23 Hakkesteegt MM, Brocaar MP, Wieringa $\mathrm{MH}$, Feenstra L: The relationship between perceptual evaluation and objective multiparametric evaluation of dysphonia severity. J Voice 2008;22:138-145.

24 Fröhlich M, Michaelis D, Kruse E: Objective description of voice quality using the hoarseness diagram (in German). HNO 1998;46: 684-689.

25 Fröhlich M, Michaelis D, Strube HW, Kruse E: Acoustic voice analysis by means of the hoarseness diagram. J Speech Lang Hear Res 2000;43:706-720.

26 Behrmann A, Sulica L, He T: Factors predicting patient perception of dysphonia caused by benign vocal fold lesions. Laryngoscope 2004;114:1693-1700.

27 Hsiung MW, Pai L, Wang HW: Correlation between Voice Handicap Index and voice laboratory measurements in dysphonic patients. Eur Arch Otorhinolaryngol 2002;259: 97-99.

28 Wheeler KM, Collins SP, Sapienza CM: The relationship between VHI scores and specific acoustic measures of mildly disordered voice production. J Voice 2006;20:308-317.

29 Woisard V, Bodin S, Yardeni E, Pusch M: The Voice Handicap Index: correlation between subjective patient response and quantitative assessment of voice. J Voice 2007;21 623-631.
30 Hakkesteegt MM, Brocaar MP, Wieringa $\mathrm{MH}$, Feenstra L: Influence of age and gender on the Dysphonia Severity Index: a study of normative values. Folia Phoniatr Logop 2006;58:264-273

31 Jandrić S, Manojlović S: Quality of life of men and women with osteoarthritis of the hip and arthroplasty: assessment by WOMAC questionnaire. Am J Phys Med Rehabil 2009;88:328-335.

32 Santos PR, Daher EF, Silva GB Jr, Libório AB, Kerr LR: Quality of life assessment among haemodialysis patients in a single center: a 2-year follow-up. Qual Life Res 2009;18:541546.

33 Grässel E, Hoppe U, Rosanowski F: Grading of the Voice-Related Quality of Life Index (in German). HNO 2009;57:896-901.

$>34$ Glas K, Hoppe U, Eysholdt U, Rosanowski F: Smoking, carcinophobia and Voice Handicap Index. Folia Phoniatr Logop 2008;60: 195-198.

35 Wilson JA, Deary IJ, Millar A, Meckenzie K: The quality of life impact of dysphonia. Clin Otolaryngol 2002;27:179-182.

>36 Rasch T, Günther S, Hoppe U, Rosanowski F: Voice-related quality of life in organic and functional voice disorders. Logoped Phoniatr Vocol 2005;30:9-13.

-37 Weigelt S, Krischke S, Klotz M, Hoppe U, Köllner V, Eysholdt U, Rosanowski F: Voice Handicap Index: Instrument zur Bestimmung der subjektiven Beeinträchtigung durch organische und funktionelle Dysphonien. HNO 2004;52:751-756. 